\title{
ANALISIS KEMAMPUAN LAHAN UNTUK ARAHAN PENGGUNAAN LAHAN PADA LERENG TIMUR LAUT GUNUNG AGUNG KABUPATEN KARANGASEM-BALI
}

\author{
I Gede Budiarta ${ }^{1 *}$, I Wayan Nuarsa ${ }^{2)}$, dan I Made Adhika ${ }^{3)}$ \\ 1) Program Pasca Sarjana Program Studi Ilmu Lingkungan, Universitas Udayana \\ 2) Program Magister Ilmu Lingkungan, Universitas Udayana \\ ${ }^{3)}$ Fakultas Teknik, Universitas Udayana. \\ ${ }^{*}$ Email : budiartagd_geo@yahoo.co.id
}

\begin{abstract}
This research was conducted in the northeastern slopes of Mount Agung in Karangasem regency, Bali province. The research area is dry land with land use patterns that have not demonstrated compliance with existing land potential. On the other hand, technological advances in the field of agriculture has been growing rapidly, one by analyzing the ability of the land to determine the potential of land resources and minimize the risk of failure of farmers. The results of the analysis of land capability is expected to serve as guidelines in a more optimal use of land in accordance with expectations.

The purpose of this study was to determine the potential of land and recommends referral based land use conditions existing land capability in the area of research. The design used is descriptive design, with the main objective to provide a picture or description of land use capability and suitability of the study area. Guidelines for land capability analysis in this study refers to Arsyad (2006) and the Regulation of the Minister of Environment No. 17 Year 2009 on Guidelines for Determining Environmental Carrying Capacity in Regional Spatial Planning.

The results showed that 1) land capability class research in areas ranging from class III to class VI. Land capability class III is spread on the land unit 1, land unit 2, land unit 3, and land unit 8. Capability class IV land located on land unit 4, land unit 7, land unit 9, land unit 10 and land unit 12.Land capability classes VI located on land unit 5 , land unit 6 , and land unit $11 ; 2$ ) land use suitability value obtained was $92.85 \%$. This shows that almost the entire study area (92.85\%) is in conformity between the ability of the land and its use. The rest (7.15\%) classified as not appropriate. Suitability of the land use study area into the high criteria; 3) Referral land use adapted to the existing conditions of land units. In class III-IV land that does not meet the user or not used optimally, land use options to do that seasonal crops, plantation crops. While on a class VI land use that is not appropriate or not used optimally, land use options to do that forest production and non-agricultural land use.
\end{abstract}

Keywords: Classes of land capability, suitability of land use, land-use directives.

\section{PENDAHULUAN}

Keterbatasan kondisi fisiografis lereng timur laut Gunung Agung merupakan faktor pembatas yang menyebabkan penggunaan lahan menjadi tidak optimal, sehingga masih banyak lahan yang tidak dimanfaatkan dengan baik. MenurutHadiwidjojo (1998), keadaangeologidaerah penelitianterdiridari batuan gunungapi Gunung Agung (Qva), yang mencakup wilayah Desa Datah, Dukuh, Tulamben, Kubu, Baturinggit, dan Sukadana serta Tuff dan endapan lahar Buyan-Bratan dan Batur (Qbb) terdapat pada wilayah Desa Ban. Berdasarkananalisis Peta Hidrologi Bali skala 1: 250.000 dan Peta Tanah Tinjau Bali Tahun 1970, rata-rata kandunganair tanah di daerah penelitian tergolong rendah dengan debit 0,1 liter/detik. Terdapat jenistanahRegosol Kelabu di Desa Datah, Dukuh, Tulamben, Kubu, Baturinggit, dan Sukadana; serta Regosol Cokelat di wilayah Desa Ban, dan sebagian Desa Sukadana. Data dari Badan Pusat Statistik Kabupaten Karangasem (2013) menunjukkan curah hujan di daerah lereng timur laut Gunung Agung tergolong rendah, yaitu \pm sebesar $1.300 \mathrm{~mm}$ per tahun dengan rerata $114 \mathrm{~mm}$ per bulan. Curah hujan tertinggi terjadi pada bulan Januari, yaitu sebesar $207 \mathrm{~mm}$, sedangkan curah hujan terendah terjadi pada bulan Mei dan Juni sebesar $23 \mathrm{~mm}$.

Belum optimalnya penggunaan lahan di daerah penelitian terlihat dari adanya lahan-lahan kosong yang tersebar di beberapa wilayah. Mengamati kondisi eksisting penggunaan lahan pada daerah penelitian, ada kecenderungan bahwa petani belum adaptif terhadap perkembangan metode bertani yang lebih relevan. Pemanfaatan lahan yang tidak memperhatikan potensi lahan, di samping memberikan resiko kegagalan juga dapat memicu terjadinya degradasi lingkungan. Sehingga dengan 
demikian masukan metode yang adaptif dan mampu menjadi solusi alternatif dalam upaya memajukan pertanian di daerah penelitian sangat perlu untuk dikembangkan.

Tujuan yang hendak dicapai dari penelitian ini adalah :

1. Memetakan kelas kemampuan lahan pada lereng sebelah timur laut Gunung Agung.

2. Mengevaluasi kesesuaian antara penggunaan lahan dan kelas kemampuan lahan pada lereng sebelah timur laut Gunung Agung.

3. Merekomendasikan arahan penggunaan lahan berdasarkan kondisi kemampuan lahan dan penggunaan lahan eksisting pada daerah penelitian.

\section{METODE PENELITIAN}

\subsection{Lokasi dan Waktu Penelitian}

Penelitian dilakukan selama 6 (enam) bulan yaitu bulan Oktober 2013 sampai dengan bulan April 2014 di di lerengtimurlautGunungAgung, Kabupaten Karangasem-Bali.

\subsection{Prosedur Penelitian}

1. Langkah pertama untuk menentukan kelas kemampuan lahan daerah penelitian adalah membuat peta unit lahan. Unit lahan merupakan sebidang lahan yang memiliki kondisi sama dalam hal bentuk lahan, jenis tanah, kemiringan lereng, dan penggunaan lahan (Sitorus, 1985). Unit lahan ini diturunkan dari beberapa peta yaitu peta jenis tanah, peta kemiringan lereng, dan peta penggunaan lahan. Ketiga peta kemudian ditumpangsusunkan sehingga menghasilkan peta unit lahan. Sifat homogen pada unit lahan akan memudahkan proses penelitian karena unit-unit lahan yang sama akan diwakili oleh satu unit.

2. Pengumpulan data secara langsung terkait kualitas dan karakteristik lahan yang dibutuhkan dalam mengungkap potensi lahan di daerah penelitian. Kualitas dan karakteristik lahan ini kemudian dianalisis berdasarkan pedoman penelitian. Data dan analisisnya akan memberikan gambaran bagaimana kelas kemampuan dan kesesuaian penggunaan lahan yang terdapat pada daerah penelitian.

3. Pedoman penentuan kelas kemampuan lahan pada penelitian ini adalah pedoman yang dirujuk dari Arsyad (2006). Sementara pedoman penentuan kesesuaian penggunaan lahan adalah Lampiran Peraturan Direktur Jenderal Rehabilitasi Lahan dan Perhutanan Sosial (RLPS) Nomor : P.04/V-Set/2009 Tanggal 05 Maret 2009.

Secara lebih rinci, cara penentuan kelas kemampuan lahan dapat dilihat pada Tabel 1.

Tabel 1 Pedoman Penentuan Kemampuan Lahan

\begin{tabular}{|c|c|c|c|c|c|c|c|c|c|}
\hline \multirow{2}{*}{ No } & \multirow{2}{*}{$\begin{array}{c}\text { Faktor Pembatas } \\
\text { Sifat Tanah }\end{array}$} & \multicolumn{8}{|c|}{ Kelas Kemampuan Lahan } \\
\hline & & $T$ & il & III & IV & $\bar{v}$ & $\mathrm{~V}$ & $\mathrm{VH}$ & VIII \\
\hline 1 & Tekstur lapisan atas $(40 \mathrm{~cm})$ & $t 1,12,13$ & t1, 12,13 & $41, t 2, t 3,14$ & $11,22,13, t 4$ & (") & $t 1,22,3,14$ & $11,2,13,44$ & t3 \\
\hline 2 & Tekstur lapisan bawah & Sda & $5 \mathrm{da}$ & Sda & Sda & (1) & Sda & Sda & t3 \\
\hline 3 & Lereng Permukaan & A & B & $\mathrm{c}$ & $\mathrm{D}$ & $E$ & $\mathrm{~F}$ & G & $(4)$ \\
\hline 4 & Drainase & oo/d1 & d2 & $d 3$ & $\mathrm{~d} 4$ & $\left({ }^{* t}\right)$ & $(")$ & (") & $(")$ \\
\hline 5 & Kedalaman efektif tanah & ko & $k 1$ & $\overline{k 2}$ & $\mathrm{k} 2$ & $(n)$ & k3 & ()$\left.^{*}\right)$ & ()$\left.^{*}\right)$ \\
\hline 6 & Tingkat erosi & $\overline{e 0}$ & $e^{1}$ & $\mathrm{e} 2$ & $\mathrm{e}^{3}$ & $(* *)$ & $\overline{e 4}$ & $\overline{e 5}$ & $(7)$ \\
\hline 7 & Keriki/batuan & bo & bo & b1 & $\mathrm{b} 2$ & $b 3$ & $(*)$ & $(*)$ & 64 \\
\hline 8 & Ancaman banjir & 00 & 01 & 02 & 03 & 04 & ()$\left.^{*}\right)$ & $(")$ & ()$\left.^{*}\right)$ \\
\hline
\end{tabular}

Sumber : Arsyad (2006); PerMen LH No. 17 Tahun 2009.

\subsection{Analisis Data}

Penelitian ini menitikberatkan pada tiga aspek, yaitu klasifikasi kemampuan lahan, penentuan kesesuaian penggunaan lahan, serta rekomendasi penggunaan lahan. Pedoman penentuan kemampuan lahan yang digunakan dalam penelitian ini adalah pedoman yang dikemukakan oleh Arsyad (2006) serta Peraturan Menteri Lingkungan Hidup
Nomor 17 Tahun 2009. Sementara untuk menentukan kesesuaian penggunaan lahan (KPL) daerah penelitian, pedoman yang digunakan adalah Lampiran Peraturan Direktur Jenderal Rehabilitasi Lahan dan PerhutananSosial (RLPS) Nomor : P.04/ V-Set/2009 Tanggal 05 Maret 2009. Klasifikasi nilai kesesuaian penggunaan lahan ditentukan menggunakan formula: 


\section{P S}

$\mathrm{KPL}=\frac{}{\text { Luas Daerah }} \times 100 \%$

Sumber: Lampiran Peraturan Direktur Jenderal Rehabilitasi Lahan dan Perhutanan Sosial (RLPS) Nomor : P.04/V-Set/2009 Tanggal : 05 Maret 2009.

Ket:

KPL = Kesesuaian Penggunaan Lahan

LPS (ha) = luas penggunaan lahan yang sesuai di daerah penelitian.

Luas daerah (ha) = luas daerah penelitian.

Klasifikasinilaikesesuaian penggunaan lahan (KPL)disajikanpada Tabel 2.

Tabel 2 Klasifikasi Nilai Kesesuaian Penggunaan Lahan

\begin{tabular}{cccc}
\hline No & Nilai KPL & Kelas & Skor \\
\hline$(1)$ & $(2)$ & $(3)$ & $(4)$ \\
1 & $>75 \%$ & Tinggi & 1 \\
2 & $40-75 \%$ & Sedang & 3 \\
3 & $<40 \%$ & Rendah & 5 \\
\hline
\end{tabular}

\section{HASIL DAN PEMBAHASAN}

\subsection{KemampuanLahan Daerah Penelitian}

Menentukan kelas kemampuan lahan di daerah penelitian merupakan salah satu tujuan utama dalam penelitian ini. Diperlukan beberapa tahapan agar dapat menentukan bagaimana kondisi kemampuan lahan yang ada pada daerah penelitian. Parameter yang digunakan untuk menentukan kemampuan lahan dalam penelitian ini mengacu kepada pedoman kemampuan lahan Arsyad (2006), serta Peraturan Menteri Lingkungan Hidup Nomor 17 Tahun 2009 Tentang Pedoman Penentuan Daya
Dukung Lingkungan Hidup Dalam Penataan Ruang Wilayah.

Lebih detil mengenai kemampuan lahan pada daerah penelitian dapat dilihat pada Tabel 3 .

Berdasarkan data pada Tabel 3, dapat diketahui bahwa kelas kemampuan lahan pada unit lahan 1 adalah kelas III, dengan faktor penghambat/ pembatas berupa kedalaman efektif tanah (k). Kemampuan lahan pada unit lahan 1 ini tergolong cukup tinggi karena lahan kelas III dapat digunakan untuk jenis tanaman semusim. Menurut PerMen LH Nomor 17 Tahun 2009, lahan kelas III dapat dimanfaatkan untuk berbagai penggunaan, di antaranya untuk pertanian tanaman semusim, tanaman yang memerlukan pengolahan tanah, tanaman rumput, padang rumput, hutan produksi, hutan lindung, dan cagar alam. Sementara untuk penggunaan nonpertanian, lahan kelas III dapat digunakan untuk kegiatan rekreasi serta obyek penelitian. Wahyuaskari (2010) menyatakan bahwa tanah pada lahan kelas III sesuai untuk segala jenis usaha pertanian dengan tindakan pengawetan tanah yang khusus seperti pembuatan terasering, pergiliran tanaman dan sistem penanaman berjalur. Untuk mempertahankan kesuburan tanah perlu pemupukan.

Kemampuan lahan pada unit lahan 2 juga tergolong kelas III dengan faktor pembatas utama berupa tekstur tanah (t), dan kedalaman efektif tanah (k). Potensi kemampuan lahan pada unit lahan 2 tergolong cukup tinggi. Seperti halnya unit lahan 1, unit lahan 2 juga dapat dimanfaatkan untuk berbagai penggunaan, misalnya untuk tanaman semusim, tanaman perkebunan, tanaman yang memerlukan pengolahan tanah, tanaman rumput, padang rumput, hutan produksi, hutan lindung dan suaka marga satwa.

Unit lahan 3 memiliki kemampuan lahan kelas III dengan faktor pembatas/penghambat berupa

Tabel 3 Kemampuan Lahan Pada Daerah Penelitian

\begin{tabular}{|c|c|c|c|c|c|c|c|c|c|c|}
\hline \multirow[b]{2}{*}{ No } & \multirow[b]{2}{*}{ Unit Lahan } & \multicolumn{8}{|c|}{ Faktor Penghambat/Pembatas } & \multirow{2}{*}{$\begin{array}{c}\text { Kelas } \\
\text { Kemampuan } \\
\text { lahan }\end{array}$} \\
\hline & & $\begin{array}{l}\text { Tekstur } \\
\text { atas }\end{array}$ & $\begin{array}{l}\text { Tekstur } \\
\text { Bawah }\end{array}$ & $\begin{array}{c}\text { Lereng } \\
\text { Permukaan }\end{array}$ & Drainase & $\begin{array}{c}\text { Kedalaman } \\
\text { efektif }\end{array}$ & Erosi & $\begin{array}{l}\text { Kerikill } \\
\text { batuan }\end{array}$ & Banjir & \\
\hline (1) & (2) & (3) & (4) & $(5)$ & (6) & $(7)$ & (8) & (9) & (10) & $(11)$ \\
\hline 1 & IN8, A, Reg. Kel., P & $t_{2}$ & $t_{2}$ & lo & $\mathrm{do}_{0} / \mathrm{d}_{1}$ & $k_{1}$ & $\mathrm{e}_{1}$ & bo & 00 & III \\
\hline 2 & 2N7, B, Reg. Kel., P & 14 & $t_{5}$ & $l_{1}$ & $\mathrm{~d}_{0} / \mathrm{d}_{1}$ & $k_{1}$ & $e_{1}$ & $b_{0}$ & 0. & III \\
\hline 3 & 3N8, A, Reg. Kel., Tg & $t_{4}$ & $t_{5}$ & 10 & $\mathrm{~d}_{0} / \mathrm{d}_{1}$ & $\mathrm{k}_{2}$ & $e_{1}$ & $b_{1}$ & 00 & III \\
\hline 4 & $4 N 6$, C, Reg, Kel., P & $t_{4}$ & $t_{5}$ & $\mathrm{I}_{2}$ & $\mathrm{~d}_{2}$ & $k_{2}$ & $e_{2}$ & $b_{1}$ & 00 & IV \\
\hline 5 & $5 N 7$, B, Reg. Cok., Lk & $t_{4}$ & $t_{5}$ & $I_{1}$ & $d_{2}$ & $k_{3}$ & $e_{1}$ & $b_{1}$ & 00 & VI \\
\hline 6 & $6 N 7$, B, Reg. Kel., Lk & $t_{5}$ & $t_{5}$ & $I_{1}$ & $\mathrm{~d}_{0} / \mathrm{d}_{1}$ & $k_{3}$ & $e_{1}$ & $b_{2}$ & 00 & $\mathrm{VI}$ \\
\hline 7 & 7N8, A, Reg. Kel., Lk & $t_{5}$ & $t_{5}$ & 10 & $d_{0} / d_{1}$ & $k_{2}$ & $e_{1}$ & $b_{1}$ & 00 & IV \\
\hline 8 & 8NT, B, Reg. Cok, P & $t_{2}$ & $t_{4}$ & it & $d_{0} / d_{1}$ & $k_{1}$ & $e_{1}$ & bo & 00 & III \\
\hline 9 & $9 N 7, \mathrm{~B}$, Reg Cok., Tg & $t_{2}$ & $t_{4}$ & 11 & $\mathrm{~d}_{0} / \mathrm{d}_{1}$ & $k_{1}$ & $e_{1}$ & $b_{1}$ & 00 & IV \\
\hline 10 & $10 \mathrm{N7}$, B, Reg. Kel, Tg & $t_{4}$ & $t_{4}$ & $i_{1}$ & $d_{d} / d_{i}$ & $k_{2}$ & $e_{1}$ & $b_{0}$ & 00 & IV \\
\hline 11 & 111NG, C, Reg. Kel, Lk & $t_{5}$ & $t_{5}$ & $\mathrm{I}_{2}$ & $d_{2}$ & $k_{3}$ & $\mathrm{e}_{2}$ & $b_{2}$ & 00 & VI \\
\hline 12 & $12 \mathrm{N7}$, B, Reg. Kel., Tg & $t_{5}$ & $t_{5}$ & $\mathrm{I}_{2}$ & $d_{d} / d_{1}$ & $k_{2}$ & $e_{1}$ & $b_{1}$ & 00 & IV \\
\hline
\end{tabular}

Sumber :Analisis Data Primer (2014) 
kedalaman efektif tanah (k) dan kerikil/batuan (b). Potensi kemampuan lahan pada unit lahan 3 tergolong cukup tinggi. Lahan ini dapat dipergunakan untuk berbagai penggunaan. Hal ini tercantum dalam PerMen LH No 17 Tahun 2009 yang digunakan sebagai pedoman penentuan kemampuan lahan daerah penelitian, selain literatur lain yang mendukung, seperti Arsyad (2006).

Unit lahan 4 mampunyai kemampuan lahan kelas IV, dengan beberapa faktor pembatas, di antaranya adalah kedalaman efektif tanah (k), keadaan erosi (e), dan kerikil/batuan (b). Kemampuan lahan pada unit ini tergolong sedang, karena hambatan dan ancaman kerusakan pada lahan kelas IV lebih besar dari pada lahan kelas III. Pilihan tanaman pada lahan kelas IV juga lebih terbatas. Jika digunakan untuk tanaman semusim diperlukan pengelolaan yang lebih hati-hati dan tindakan konservasi yang lebih sulit diterapkan dan dipelihara. Tindakan tersebut seperti pembuatan teras bangku, saluran bervegatasi dan dam penghambat, di samping tindakan yang dilakukan untuk memelihara kesuburan dan kondisi fisik tanah. Hal ini sesuai dengan uraian dari Wahyuaskari (2010), yang menyatakan bahwa tanah pada lahan kelas IV ini masih dapat dijadikan lahan pertanian dengan tingkatan pengawetan tanah yang lebih khusus dan lebih berat.

Kemampuan lahan pada unit lahan 5 berada pada kelas VI, dengan faktor pembatas berupa kedalaman efektif tanah (k). Kemampuan lahan ini lebih buruk dari kemampuan lahan pada unit-unit lahan sebelumnya. Potensi unit lahan 5 tergolong rendah karena lahan pada kelas ini mempunyai faktor penghambat berat yang menyebabkan penggunaan tanah sangat terbatas. Lahan kelas VI mempunyai ancaman kerusakan yang sangat sulit untuk dihilangkan. Namun demikian lahan kelas VI masih dapat digunakan untuk beberapa penggunaan, seperti yang disebutkan dalam Arsyad (1989), penggunaan lahan yang dapat diupayakan adalah hutan produksi, hutan lindung dan cagar alam.

Kemampuan lahan pada unit lahan 6 masuk dalam kategori kelas VI. Adapun faktor penghambatnya yaitu kedalaman efektif tanah (k) dan kerikil/batuan (b). Kemampuan lahan ini sama dengan kemampuan lahan pada unit lahan 5 . Potensinya tergolong rendah sehingga penggunaannya pun sama seperti unit lahan 5 , yaitu hutan produksi, hutan lindung dan cagar alam. Lahan kelas VI dapat juga dimanfaatkan untuk penggunaan nonpertanian, misalnya tempat rekreasi dan obyek penelitian.

Kemampuan lahan pada unit lahan 7 tergolong kelas IV, dengan faktor penghambat/pembatas berupa kedalaman efektif tanah (k). Potensi kemampuan lahan pada unit lahan 7 tergolong sedang. Lahan ini memang dapat digunakan untuk tanaman semusim namun diperlukan pengelolaan yang lebih hati-hati dan tindakan konservasi yang lebih sulit. Memelihara kesuburan dan kondisi fisik tanah sangat perlu untuk dilakukan pada lahan kelas IV. Secara lebih rinci, lahan kelas IV dapat digunakan untuk tanaman semusim dan tanaman pertanian dan pada umumnya, tanaman rumput, hutan produksi, padang penggembalaan, hutan lindung dan cagar alam.

Kemampuan lahan pada unit lahan 8 tergolong kelas III, dengan faktor penghambat berupa kedalaman efektif tanah (k), keadaan erosi (e), dan kerikil/batuan (b). Potensi kemampuan lahan yang dimiliki tergolong cukup tinggi. Lahan ini dapat digunakan untuk berbagai keperluan. Seperti yang telah diuraikan pada unit lahan lain yang tergolong kelas III, unit lahan ini dapat dipergunakan untuk pertanian tanaman semusim, tanaman yang memerlukan pengolahan tanah, tanaman rumput, padang rumput, hutan produksi, hutan lindung, serta cagar alam. Sementara untuk penggunaan nonpertanian, lahan kelas III ini dapat digunakan untuk kegiatan rekreasi serta obyek penelitian (Arsyad, 1989).

Unit lahan 9 memiliki kemampuan lahan yang tergolong kelas IV, dengan faktor pembatas berupa kerikil/batuan (b). Potensi lahan pada unit lahan 9 tergolong sedang. Hambatan dan ancaman kerusakan tanah lebih besar dari kelas III, dan pilihan tanaman juga lebih terbatas. Perlu pengelolaan hati-hati untuk tanaman semusim, dan tindakan konservasi lebih sulit diterapkan. Penggunaan lahan yang dapat diupayakan antara lain tanaman semusim dan tanaman pertanian pada umumnya, tanaman rumput, hutan produksi, padang penggembalaan, hutan lindung, dan suaka alam.

Kemampuan lahan pada unit lahan 10 adalah kelas IV, dengan faktor pembatas/penghambat utama yaitu kedalaman efektif tanah (k). Potensi kemampuan lahan pada unit lahan 10 tergolong sedang. Pilihan tanaman yang dapat diusahakan lebih terbatas. Jika digunakan untuk tanaman semusim maka diperlukan diperlukan pengelolaan yang lebih hati-hati dan tindakan konservasi yang lebih sulit untuk diterapkan. Namun demikian, lahan kelas IV sesungguhnya dapat digunakan untuk tanaman semusim dan tanaman pertanian dan pada umumnya.

Kemampuan lahan pada unit 11 adalah kelas VI dengan faktor penghambat/faktor pembatas berupa kedalaman efektif tanah (k). Potensi lahan pada unit lahan 11 tergolong rendah. Unit lahan 11 mempunyai faktor penghambat berat yang menyebabkan penggunaan lahan sangat terbatas karena mempunyai ancaman kerusakan yang sulit dihilangkan. Umumnya lahan kelas VI terletak pada lereng curam, sehingga jika dipergunakan untuk penggembalaan dan hutan produksi harus dikelola dengan baik untuk menghindari erosi. 
Unit lahan 12 tergolong memiliki kemampuan lahan kelas IV, dengan faktor penghambat atau pembatas berupa kedalaman efektif tanah (k) dan kerikil/batuan (b). Potensi kemampuan lahannya tergolong sedang. Hal ini disebabkan oleh karena hambatan dan ancaman kerusakan tanah pada lahan ini lebih besar dari kelas III, dan pilihan tanaman juga terbatas. Perlu pengelolaan hati-hati untuk tanaman semusim, tindakan konservasi juga lebih sulit diterapkan. Jika digunakan untuk tanaman semusim maka diperlukan pengelolaan yang lebih hati-hati dan tindakan konservasi yang lebih sulit untuk diterapkan.

Berdasarkan hasil analisis dari masing-masing unit lahan yang ada di daerah penelitian, secara umum kemampuan lahan di daerah penelitian menunjukkan potensi yang cukup tinggi, karena sebagian besar unit lahan berada pada kisaran kemampuan lahan kelas III hingga kelas IV. Lahanlahan tersebut dapat dipergunakan untuk berbagai penggunaan, baik pertanian maupun nonpertanian. Dengan kemampuan lahan yang cukup tinggi ini semestinya pertanian lahan kering pada daerah penelitian dapat berjalan dengan lebih intensif.

Secara lebih rinci mengenai persebaran kelas kemampuan lahan pada daerah penelitian, dapat diamati pada Gambar 1.

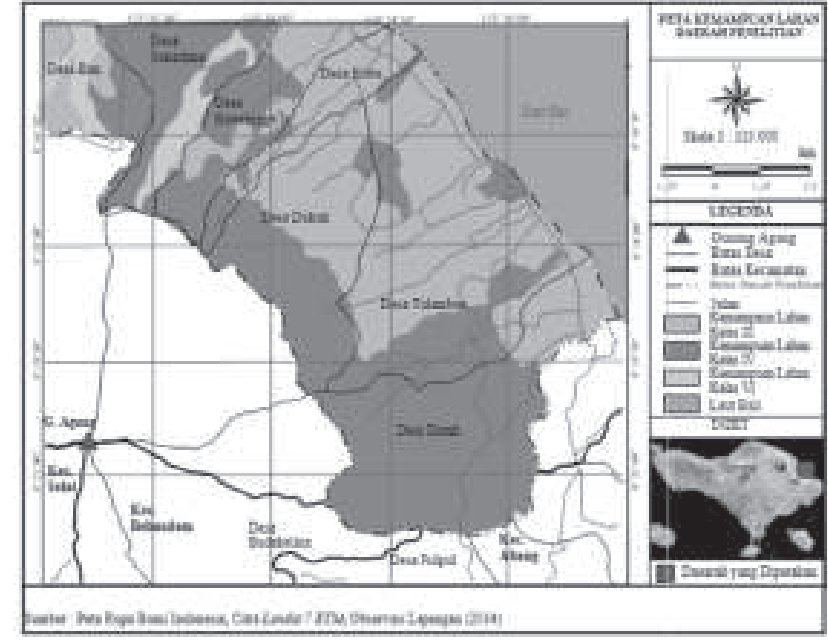

Gambar 1. Peta Kemampuan Lahan Daerah Penelitian

Berdasarkan Gambar 5.1, kemampuan lahan kelas III dan kelas IV merupakan kelas kemampuan lahan yang paling dominan $(96,03 \%)$ pada daerah penelitian. Hanya sebagian kecil (3,97 \%) dari wilayah penelitian yang memiliki kemampuan lahan kelas VI. Hal ini menunjukkan bahwa daerah penelitian memiliki potensi yang cukup tinggi untuk dikembangkan, khususnya dalam bidang pertanian lahan kering. Potensi kemampuan lahan yang cukup

Tabel 4. Kesesuaian Penggunaan Lahan Daerah Penelitian

\begin{tabular}{|c|c|c|c|c|c|}
\hline UL & Kelas & $\begin{array}{l}\text { Penggunaan } \\
\text { Lahan }\end{array}$ & Faktor Pembatas & $\begin{array}{l}\text { Luas } \\
\text { (ha) }\end{array}$ & Evaluasi Kesesuaian \\
\hline (1) & (2) & (3) & (4) & (5) & (6) \\
\hline 1 & III $k_{1}$ & $\begin{array}{l}\text { Perkebunan } \\
\text { rakyat }\end{array}$ & $\begin{array}{l}\text { Kedalaman efektif tana: sedang }(90-50 \\
\mathrm{cm})\end{array}$ & $1.287,75$ & $\begin{array}{l}\text { Sesuai, namun perlu } \\
\text { diintensifkan }\end{array}$ \\
\hline 2 & III t $\mathrm{t}_{1}$ & $\begin{array}{l}\text { Perkebunan } \\
\text { rakyat }\end{array}$ & $\begin{array}{l}\text { Tekstur agak kasar, kedalaman efektif } \\
\text { tanah: sedang }(90-50 \mathrm{~cm})\end{array}$ & $1.958,4$ & $\begin{array}{l}\text { Sesuai, namun perlu } \\
\text { diintensifkan }\end{array}$ \\
\hline 3 & $\| I k_{1} b_{0}$ & Tegalan & $\begin{array}{l}\text { Kedalaman efektif tanah: sedang }(90-50 \\
\mathrm{cm}) \text {, sedikit kerikil/batuan }\end{array}$ & 948,6 & $\begin{array}{l}\text { Sesuai, namun perlu } \\
\text { diintensifkan }\end{array}$ \\
\hline 4 & $\begin{array}{lll}\text { IV } & k_{2} & e_{2} \\
b_{1}\end{array}$ & $\begin{array}{l}\text { Perkebunan } \\
\text { rakyat }\end{array}$ & $\begin{array}{l}\text { Kedalaman tanah tergolong dangkal, } \\
\text { banyak kerikil }\end{array}$ & $1.014,05$ & $\begin{array}{l}\text { Sesuai, namun perlu } \\
\text { diversifikasi }\end{array}$ \\
\hline 5 & $\mathrm{VI} \mathrm{k}_{3}$ & Lahan kosong & $\begin{array}{l}\text { Kedalaman tanah tergolong sangat } \\
\text { dangkal, banyak kerikil/batuan }\end{array}$ & 152,15 & $\begin{array}{l}\text { Tidak sesuai, perlu } \\
\text { dilakukan perubahan }\end{array}$ \\
\hline 6 & $\mathrm{VI} \mathrm{k}_{3}$ & Lahan kosong & $\begin{array}{l}\text { Kedalaman tanah tergolong sangat } \\
\text { dangkal, banyak kerikil/batuan }\end{array}$ & 188,70 & $\begin{array}{l}\text { Tidak sesuai, perlu } \\
\text { dilakukan perubahan }\end{array}$ \\
\hline 7 & $I V k_{2} b_{1}$ & Lahan kosong & $\begin{array}{l}\text { Kedalaman tanah tergolong dangkal, } \\
\text { banyak kerikil }\end{array}$ & 302,60 & $\begin{array}{l}\text { Tidak sesuai, } \\
\text { perlu dilakukan perubahan }\end{array}$ \\
\hline 8 & III k & $\begin{array}{l}\text { Perkebunan } \\
\text { Rakyat }\end{array}$ & $\begin{array}{l}\text { Kedalaman efektif tanah sedang }(90-50 \\
\mathrm{cm})\end{array}$ & 269,45 & $\begin{array}{l}\text { Sesuai, namun perlu } \\
\text { diintensifkan }\end{array}$ \\
\hline 9 & $I V b_{1}$ & Tegalan & $\begin{array}{l}\text { Kerikil/batuan tergolong sedang }(15-50 \\
\%)\end{array}$ & 181,9 & $\begin{array}{l}\text { Sesuai, namun perlu } \\
\text { diintensifkan }\end{array}$ \\
\hline$\overline{10}$ & IV $k_{2}$ & Tegalan & $\begin{array}{l}\text { Kedalaman tanah tergolong dangkal } \\
(50-25 \mathrm{~cm})\end{array}$ & $3.085,50$ & $\begin{array}{l}\text { Sesuai, namun perlu } \\
\text { diintensifkan }\end{array}$ \\
\hline 11 & $\mathrm{VI} \mathrm{k}_{3}$ & Lahan kosong & Tanah sangat dangkal, banyak batuan & 46,75 & $\begin{array}{l}\text { Tidak sesuai, } \\
\text { perubahan }\end{array}$ \\
\hline 12 & $I V k_{2}$ & Tegalan & Tanah dangkal $(50-25 \mathrm{~cm})$ & 222,70 & $\begin{array}{l}\text { Sesuai, namun perlu } \\
\text { diintensifkan }\end{array}$ \\
\hline
\end{tabular}

Sumber:Interpretasi Peta Rupa Bumi, Observasi Lapangan (2013), Analisis Laboratorium Tanah Universitas Udayana, 2014. 
tinggi ini seharusnya diimbangi dengan penggunaan lahan yang optimal, sehingga aktivitas pertanian dapat memberikan hasil sesuai dengan harapan.

\subsection{KesesuaianPenggunaanLahan Daerah Penelitian}

Berdasarkan hasil penelitian, maka kesesuaian penggunaan lahan pada daerah penelitian tergolong tinggi, dengan persentase kesesuaian 92,85\%. Ini menunjukkan bahwa hampir seluruh bagian wilayah penelitian $(92,85 \%)$ adalah sesuai antara kelas kemampuan lahan dan penggunaan lahannya. Sementara sebagian kecil lagi (7,15\%) masih belum menunjukkan kesesuaian.

Secara rinci, kondisi kesesuaian penggunaan lahan pada daerah penelitian dapat dilihat pada Tabel 4.

Berdasarkan perhitungan, persentase kesesuaian penggunaan lahan daerah penelitian adalah 92,85\%. Ini menunjukkan bahwa sebagian besar $(92,85) \%$ dari total luas daerah penelitian memiliki kesesuaian antara penggunaan lahan dan potensi lahan yang ada (kemampuan lahan). Persentase ini berada pada kisaran tinggi, dengan skor 1 . Tergolong kisaran tinggi karena persentase kesesuaiaannya mencapai lebih dari 75 $\%$. Secara lebih rinci mengenai kondisi kesesuaian penggunaan lahan daerah penelitian dapat diamati pada Gambar 2.

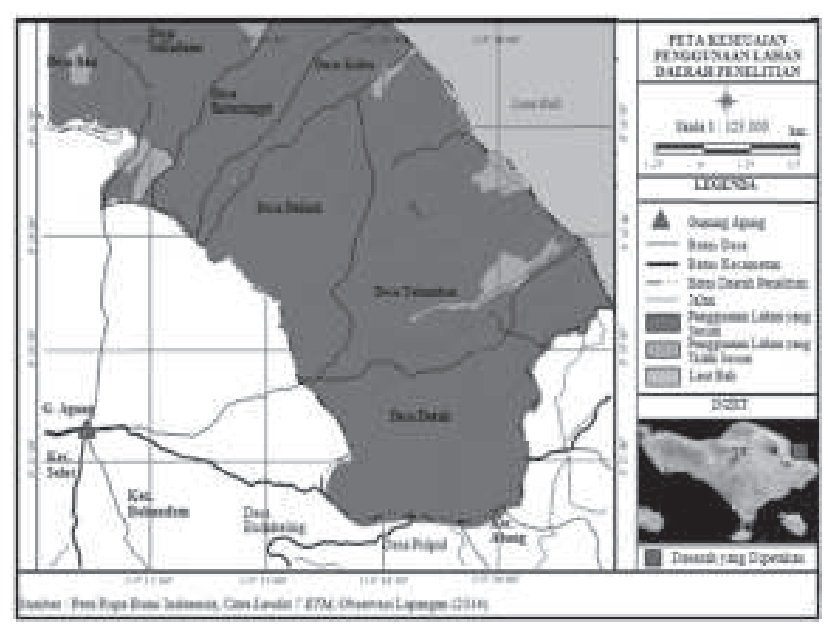

Gambar 2. Peta Kesesuaian Penggunaan Lahan Daerah Penelitian

\subsection{Arahan Penggunaan Lahan Daerah Penelitian}

Rekomendasi penggunaan lahan yang dikemukakan dalam pembahasan ini disusun berdasarkan kondisi penggunaan lahan eksisting pada daerah penelitian. Kemampuan lahan pada unit lahan 1, unit lahan 2 , unit lahan 3 dan unit lahan 8 adalah yang paling potensial, yaitu kelas III. Penggunaan lahan pada unit lahan 1, unit lahan 2 dan unit lahan 8 adalah perkebunan rakyat, namun tidak intensif. Sementara pada unit lahan 3 penggunaan lahan yang dominan adalah tegalan. Secara umum terdapat kesesuaian antara potensi dan penggunaan lahan pada unit-unit lahan tersebut. Namun demikian, potensi lahan yang ada seharusnya dimanfaatkan seoptimal mungkin. Selain untuk perkebunan (tanaman tahunan), lahan kelas III memiliki potensi untuk pertanian tanaman musiman, seperti yang tercantum di dalam PerMen LH No 19 Tahun 2007. Seharusnya unit lahan 1, unit lahan 2, unit lahan 3 , dan unit lahan 8 diintensifkan dengan memadukan antara tanaman tahunan dan tanaman semusim sebagai tanaman sela untuk memperoleh hasil seperti yang diinginkan. Hal ini didukung oleh Pranowo dan Purwanto (2011), yang menyatakan bahwa penanaman tanaman sela di antara tanaman perkebunan merupakan salah satu usaha optimalisasi lahan pemanfaatan lahan untuk meningkatkan produktivitas lahan melalui diversifikasi tanaman.

Menurut Wahyuaskari (2010), lahan kelas III sesuai untuk segala jenis usaha pertanian dengan tindakan pengawetan tanah yang khusus seperti pembuatan terasering, pergiliran tanaman dan sistem penanaman berjalur. Untuk mempertahankan kesuburan tanah perlu pemupukan. Sementara menurut USDA dalam Suripin (2002), lahan kelas III memiliki kemampuan agak baik namun usahapertanianyang dapat dilakukan agakterbatas. Untuk dapat melakukan usaha pertanian diperlukan investasiberupairigasi, drainase, pemupukan, danpencegahanerosi.

Berdasarkan alternatif penggunaan lahan tersebut maka rekomendasi penggunaan lahan pada unit lahan kelas III pada daerah penelitian adalah tanaman semusim dan tanaman yang memerlukan pengolahan lahan. Hal ini dimaksudkan agar lahanlahan yang potensial tersebut dapat dimanfaatkan secara optimal, sehingga dapat memberikan hasil seperti yang diharapkan. Penggunaan lahan yang optimal pada akhirnya diharapkan dapat meningkatkan kesejahteraan petani, khususnya para petani lahan kering yang berada di lereng Gunung Agung.

Secara lebih detil mengenai arahan penggunaan lahan pada daerah penelitian dapat diamati pada Tabel 5. 
Tabel 5. Rekomendasi Arahan Penggunaan Lahan Daerah Penelitian

\begin{tabular}{|c|c|c|c|c|c|c|}
\hline UL & Kelas & $\begin{array}{l}\text { Penggunaan } \\
\text { Lahan } \\
\text { Eksisting }\end{array}$ & $\begin{array}{l}\text { Luas } \\
\text { (ha) }\end{array}$ & $\begin{array}{l}\text { Cakupan } \\
\text { Wilayah }\end{array}$ & Evaluasi Kesesuaian & $\begin{array}{l}\text { RekomendasiArahan } \\
\text { Penggunaan Lahan }\end{array}$ \\
\hline (1) & (2) & (3) & (4) & (5) & (6) & (7) \\
\hline 1 & $\|1\|$ & $\begin{array}{l}\text { Perkebunan } \\
\text { rakyat }\end{array}$ & $1,287,75$ & $\begin{array}{l}\text { Desa } \\
\text { Tulamben, } \\
\text { Baturinggit, } \\
\text { Kubu, Datah }\end{array}$ & $\begin{array}{l}\text { Sesuai, namun perlu diintensifkan, dilakukan } \\
\text { diversifikasi, disesuaikan dengan kondisi eksisting } \\
\text { wilayah. Tanaman semusim adalah contohnya. }\end{array}$ & $\begin{array}{l}\text { Tanaman semusim dan } \\
\text { tanaman yang memerlukan } \\
\text { pengolahan tanah. }\end{array}$ \\
\hline 2 & $\mathrm{H} \| \mathrm{I}$ & $\begin{array}{l}\text { Perkebunan } \\
\text { rakyat }\end{array}$ & $1.958,4$ & $\begin{array}{l}\text { Desa Data, } \\
\text { Dukuh, Kubu, } \\
\text { Baturinggit }\end{array}$ & $\begin{array}{l}\text { Sesuai, namun perlu diintensifkan, dilakukan } \\
\text { diversivikasi, disesuaikan dengan potensi wilayah. } \\
\text { Misalnya tanaman semusim. }\end{array}$ & $\begin{array}{l}\text { Tanaman semusim dan } \\
\text { tanaman yang memerlukan } \\
\text { pengolahan tanah. }\end{array}$ \\
\hline 3 & III & Tegalan & 948,6 & $\begin{array}{l}\text { Desa } \\
\text { Baturinggit, } \\
\text { Kubu, } \\
\text { Tulamben, } \\
\text { Datah }\end{array}$ & $\begin{array}{l}\text { Sesuai, namun perlu dintensifkan, dilakukan } \\
\text { diversivikasi, disesuaikan dengan potensi wilayah. } \\
\text { Misalnya tanaman semusim. }\end{array}$ & $\begin{array}{l}\text { Tanaman semusim dan } \\
\text { tanaman yang memerlukan } \\
\text { pengolahan tanah. }\end{array}$ \\
\hline 4 & IV & $\begin{array}{l}\text { Perkebunan } \\
\text { rakyat }\end{array}$ & $1.014,05$ & $\begin{array}{l}\text { Desa } \\
\text { Sukadana, } \\
\text { Baturinggit, Ban }\end{array}$ & $\begin{array}{l}\text { Sesuai, namun perlu adanya diversifikai } \\
\text { komoditas. }\end{array}$ & $\begin{array}{l}\text { Tanaman semusim } \\
\text { Tanaman perkebunan } \\
\text { Hutan produksi, diperlukan } \\
\text { upaya- } \\
\text { upayainvestasiberupapemupuk } \\
\text { an, pembuatanterasering. }\end{array}$ \\
\hline 5 & $\mathrm{Vl}$ & Lahan kosong & 152,15 & $\begin{array}{l}\text { Desa Ban } \\
\text { bagian tengah }\end{array}$ & $\begin{array}{l}\text { Tidak sesuai, penggunaan lahan harus } \\
\text { disesuaikan dengan kondisi wilayah. }\end{array}$ & $\begin{array}{l}\text { Hutan produksi, banyak } \\
\text { investasi diperlukan untuk } \\
\text { mencegah banjir dan erosi. }\end{array}$ \\
\hline 6 & $\mathrm{VI}$ & Lahan kosong & 188,70 & $\begin{array}{l}\text { Desa Sukadana } \\
\text { bagian selatan }\end{array}$ & $\begin{array}{l}\text { Tidak sesuai, penggunaan lahan harus } \\
\text { disesuaikan dengan kondisi eksisting wilayah. }\end{array}$ & $\begin{array}{l}\text { Hutan produksi, banyak } \\
\text { investasi diperlukan untuk } \\
\text { mencegah banjir dan erosi. }\end{array}$ \\
\hline 7 & IV & Lahan kosong & 302,60 & $\begin{array}{l}\text { Desa Sukadana } \\
\text { bagian utara }\end{array}$ & $\begin{array}{l}\text { Tidak sesuai, perlu dilakukan perubahan, } \\
\text { penggunaan lahan harus disesuaikan dengan } \\
\text { potensi wilayah. }\end{array}$ & $\begin{array}{l}\text { Tanaman semusim } \\
\text { Tanaman perkebunan } \\
\text { Hutan produksi }\end{array}$ \\
\hline 8 & III & $\begin{array}{l}\text { Perkebunan } \\
\text { rakyat }\end{array}$ & 269,45 & $\begin{array}{l}\text { Desa Ban } \\
\text { bagian barat }\end{array}$ & Sesuai, namun perlu diversifikasi tanaman. & $\begin{array}{l}\text { Tanaman semusim dan } \\
\text { tanaman yang memerlukan } \\
\text { pengolahan tanah. }\end{array}$ \\
\hline 9 & IV & Tegalan & 181,9 & $\begin{array}{l}\text { Desa Ban } \\
\text { bagian timur }\end{array}$ & $\begin{array}{l}\text { Sesuai, namun perlu diintensifkan, dilakukan } \\
\text { diversivikasi, disesuaikan dengan potensi wilayah. } \\
\text { Misalnya tanaman semusim. }\end{array}$ & $\begin{array}{l}\text { Tanaman semusim } \\
\text { Tanaman perkebunan } \\
\text { Hutan produksi }\end{array}$ \\
\hline 10 & IV & Tegalan & $3.085,50$ & $\begin{array}{l}\text { Desa } \\
\text { Sukadana, } \\
\text { Baturinggit, } \\
\text { Tulamben, } \\
\text { Datah. }\end{array}$ & $\begin{array}{l}\text { Sesuai, namun perlu diintensifkan, dilakukan } \\
\text { diversivikasi, disesuaikan dengan potensi wilayah. } \\
\text { Misalnya tanaman semusim. }\end{array}$ & $\begin{array}{l}\text { Tanaman semusim } \\
\text { Tanaman perkebunan } \\
\text { Hutan produksi }\end{array}$ \\
\hline$\overline{11}$ & V! & Lahan kosong & 46,75 & $\begin{array}{l}\text { Desa Sukadana } \\
\text { bagian selatan }\end{array}$ & $\begin{array}{l}\text { Tidak sesuai, penggunaan lahan seharusnya } \\
\text { disesuaikan dengan kondisi eksisting wilayah. }\end{array}$ & $\begin{array}{l}\text { Hutan produksi, banyak } \\
\text { investasi diperlukan untuk } \\
\text { mencegah banjir dan erosi. }\end{array}$ \\
\hline 12 & IV & Tegalan & 222,70 & $\begin{array}{l}\text { Desa Sukadana } \\
\text { bagian selatan }\end{array}$ & $\begin{array}{l}\text { Sesuai, namun perlu diintensifkan, dilakukan } \\
\text { diversivikasi, disesuaikan dengan potensi wilayah. } \\
\text { Misalnya tanaman semusim. }\end{array}$ & $\begin{array}{l}\text { Tanaman semusim } \\
\text { Tanaman perkebunan } \\
\text { Hutan produksi, diperlukan } \\
\text { upaya- } \\
\text { upayainvestasiberupapemupuk } \\
\text { an, pembuatanterasering. }\end{array}$ \\
\hline
\end{tabular}

Sumber:Interpretasi Peta Rupa Bumi, Observasi Lapangan (2013), Analisis LaboratoriumTanah Universitas Udayana (2014), PerMen LH No. 17 Tahun 2009 


\section{SIMPULAN DAN SARAN}

\subsection{Simpulan}

1. Kelas kemampuan lahan yang terdapat pada daerah lereng timur laut Gunung Agung, Karangasem-Bali berkisar antara kelas III hingga kelas VI. Kelas III persebarannya pada unit lahan 1, unit lahan 2, unit lahan 3, dan unit lahan 8. Kelas IV tersebar pada unit lahan 4, unit lahan 7, unit lahan 9, unit lahan 10, dan unit lahan 1, dan kelas VI yang tersebar pada unit lahan 5, unit lahan 6, dan unit lahan 11.

2. Kesesuaian antara kemampuan lahan dan penggunaannya pada daerah penelitian tergolong tinggi. Hampir seluruh wilayah (92,85 \%) adalah sesuai antara kemampuan dan penggunaannya, selebihnya $(7,15 \%)$ belum menunjukkan kesesuaian penggunaan lahan.

3. Arahan penggunaan lahan disesuaikan dengan kondisi eksisting unit lahan, yaitu pada unitunit lahan yang belum dimanfaatkan secara optimal, pilihan penggunaan lahan yang dapat dilakukan yaitu 1) tanaman semusim dan tanaman yang memerlukan pengolahan tanah; 2) tanaman perkebunan; 3) hutan produksi; 4) penggunaan nonpertanian.

\subsection{Saran}

Beberapa saran yang dapat diberikan berkenaan dengan studi ini adalah:

1. Diperlukan program-program penyuluhan kepada masyarakat (petani), khususnya para petani yang bermukim di daerah penelitian, agar para petani memiliki wawasan dan pemahaman dalam mengelola lahan pertanian sesuai dengan potensi lahan yang ada.

2. Potensi kemampuan lahan yang cukup tinggi pada daerah penelitian hendaknya dioptimalkan, khususnya oleh para petani.

3. Arahan penggunaan lahan hasil penelitian ini dapat dijadikan pedoman atau pembanding dalam upaya pemanfaatan lahan di daerah penelitian.

4. Perlu adanya penelitian yang lebih mendalam terkait dengan daya dukung lingkungan dan masukan teknologi konservasi pada daerah penelitian sehingga pemanfaatan lahan dapat berjalan secara simbang dan lestari.

\section{DAFTAR PUSTAKA}

Arsyad, S. 2006. Konservasi Tanah dan Air Edisi ke 2. IPB Press.Bogor

BPS Karangasem. 2013. KecamatanKubuDalam Angka2013. BadanPusatStatistikKabupaten Karangasem. Amlapura.
Hadiwidjojo, P.M.M. 1998. GeologiPulau Bali.PusatPenelitiandanPengembanganGeologi. Bandung.

Peraturan Direktur Jenderal Rehabilitasi Lahan dan Perhutanan Sosial Nomor P.04/V-Set/2009. Pedoman Monitoring dan Evaluasi DAS. 05 Maret 2009. Jakarta, Indonesia: Berita Negara Republik Indonesia Tahun 2009 Nomor 109.

Peraturan Menteri Lingkungan Hidup Nomor 17 Tahun 2009. Pedoman Penentuan Daya Dukung Lingkungan Hidup Dalam Penataan Ruang Wilayah. 22 Mei 2009. Jakarta, Indonesia.

Bappeda Bali. 2009. Peta Hidrologi Provinsi Bali Skala 1: 250.000. Badan Perencanaan Pembangunan Daerah ProvinsiBali. Denpasar.

Bappeda Bali. 2009. Peta Kemiringan Lereng Provinsi Bali Skala 1 : 250.000. Badan Perencanaan Pembangunan Daerah Provinsi Bali. Denpasar.

Bappeda Bali. 2009. Peta Penggunaan Lahan Provinsi Bali Skala 1: 250.000. Badan Perencanaan Pembangunan Daerah Provinsi Bali. Denpasar.

Bakosurtanal. 2001. Peta Rupabumi Digital Indonesia Lembar 1807-413. Badan Koordinasi Survey dan Pemetaan Nasional. Jakarta.

Lembaga Penelitian Tanah. 1970. Peta Tanah Tinjau Provinsi Bali Skala 1: 250.000. Lembaga Penelitian Tanah. Bogor.

Pranowo, Dibyo dan Purwanto, Eko Heri. 2011. "Pemanfaatan Lahan di Antara Tanaman Jambu Mete Muda di Lahan Marginal".Buletin RISTRI.Vol.2. p: 199-206.

Sitorus, S. R.P. 1985. Evaluasi Sumberdaya Lahan. TARSITO.Bandung.

Suripin. 2002. PelestarianSumberdaya Tanah dan Air. ANDI. Yogyakarta.

Wahyuaskari. 2010. "Kelas Kemampuan Lahan". http: / / wahyuaskari.wordpress.com/ akademik/kelas-kemampuan-lahan/.diakses tanggal 5Mei2011. 